\title{
Education and Employment are at two Poles- A Research using Fuzzy Cognitive Linguistic Multimaps
}

\author{
Nivetha Martin, W. Ritha, J. Merline Vinotha, I. Antonitte Vinoline
}

\begin{abstract}
The status of white collar jobs are gradually declining in India and the people are getting accustomed to just in jobs for their livelihood sustainability. The question of existence of such unfilled gaps between education and employment is still unanswered and now it has become a predicament. It is indeed a crucial period for the higher educational institutions of the nation to balance both enrollment and placement of the students amidst the prevailing competitions in the educational market. In the present days, educational sectors are becoming corporatized by institutionalizing the principles of corporate into the dictionary of academics with the argument of fostering quality in education. The management of the institutions also substantiates such kind of transition in this era of technology. Should the institutions become manufacturing companies of quality employees to make them fit into the job market, which demands excess of skills and competencies to go for a long run? The reasons for education and employment being at two poles have to be studied to develop a deeper comprehension on the grounds of such emerging crisis. This study will be fruitful to the educationalists, academic experts and educational reformers to frame certain remedial measures for rectification. To carry out this research work systematically the concept of Fuzzy Cognitive Linguistic Multimaps, which is an extension of fuzzy cognitive trimaps, is used to draw feasible concluding remarks and inferences devoid of ambiguity and uncertainty.
\end{abstract}

Keywords-Fuzzy Cognitive maps, Linguistic variable, Multimaps, Heptagonal fuzzy number, Education, Employment

\section{INTRODUCTION}

Education is the igniting weapon of human mind to conceptualize the values and knowledge of diverse concepts. Imparting quality in education is very essential and the quality must be measured based on its outcomes and not on the monetary values demanded by certain institutions. It is the sole responsibility of the higher educational educations to impart quality education for creating erudite society. One man's acquired knowledge through education must get manifested in the life of others, but presently a man's degree is not even self-benefitting. Lakhs of degree holders are excluded from the job markets who still only hope to find suitable job opportunities. The rate of unemployment in India is climbing high every year with several graduates left unemployed. Educated goes jobless and illiterate gains

Revised Version Manuscript Received on April 12, 2019.

Nivetha Martin, Department of Mathematics, Arul Anandar College (Autonomous), Karumathur, Madurai, Tamil Nadu, India

W. Ritha, Department of Mathematics, Holy Cross College (Autonomous), Tiruchirapalli, Tamil Nadu, India

J. Merline Vinotha, Department of Mathematics, Holy Cross College (Autonomous), Tiruchirapalli, Tamil Nadu, India

I. Antonitte Vinoline, Department of Mathematics, Holy Cross College (Autonomous), Tiruchirapalli, Tamil Nadu, India momentum by their own initiatives. Graduates who study for white collar jobs are performing pink and blue collar works. If this situation prevails then education and employment will become unbridgeable. The reasons for such unfilled gaps have to be analyzed effectively to frame appropriate measures to bridge the two poles. This has intended us to use the notion of fuzzy cognitive linguistic Multimaps to analyze the factors associated with the proposed problem.

Kosko [3] has greatly contributed to the development of Fuzzy Cognitive Maps (FCM) from cognitive maps initiated by Robert Axelrod [1]. FCM is basically a graphical representation of the factors of a problem and its causal effects as the nodes and edges respectively. This FCM has extensive applications in decision making predominantly in the areas of sociology and biology. One of the notable contributors to FCM models is W.B.VasanthaKanthasamy [10] who has published several books and articles based on FCM which served as the basis for other researchers to carry out their works. She has introduced the concept of Bimaps, Trimaps to FCM models in her book entitled 'Application of Bimatrices to some Fuzzy and Neutrosophic Models'.

This highly influenced and motivated us to generate Multimaps and incorporate with Linguistic FCM to develop a new model.To the best of our knowledge such FCM models are not yet disclosed in the research forum.Linguistic FCM models are consistent in nature as it deals with considerate opinion of experts. Nivetha.et.al $[5,6,7,8]$ has used linguistic FCM to model the decision making situations pertaining to environmental sustainability, environmental engineering, digitalization impacts on learning trends, customer relationship management and so on. In general if a problem has to be analyzed using FCM model, the factors and the causal relationships are determined based on the expert's opinion. The validity of the relational matrix obtained from the FCM depends on the expert's input and the reliability can be enhanced by considering several expert' opinion. The application of Multimaps provide the chances of considering all the expert's opinion and the simultaneous impacts of many factors over the other factors can be analyzed to develop comprehensive and ingenious conclusions. This is the prime advantage of using Fuzzy Cognitive Multimaps model in dealing real life applications. In this research work the notion of Multimaps is incorporated into the linguistic FCM model. The linguistic variables representing the 
connectivity of the factors are quantified interms of heptagonal fuzzy numbers, which is a new initiative taken by us, where as in the earlier works of hexagonal fuzzy numbers were used for linguistic quantification. The use of higher order fuzzy numbers will still facilitate the feasibility of decision making.

The paper is organized into the following sections: section 2 consists of the preliminaries; section 3 presents the methodology; section 4 encompasses the application of the proposed method to the problem considered for research study; section 5 discusses the results and section 6 concludes the research work.

\section{PRELIMINARIES}

\subsection{Fuzzy Cognitive Maps (FCM)}

A FCM is a directed graph with nodes and edges representing the factors of a problem and its connectivity respectively.

\subsection{Simple FCM}

A simple FCM assumes the edge weights from the finite set $\{-1,0,1\}$.

\subsection{Weighted FCM}

A weighted FCM assumes the edge weights from $[-1,1]$.

\subsection{Linguistic variable}

A variable which takes verbal values like high, medium low etc is termed as linguistic variable.

\subsection{Linguistic FCM}

Linguistic FCM assumes the edge weights from a set of defined linguistic variables

\subsection{Relational Matrix}

The matrix that represents the causal relationship between the vertices in terms of numerical values ranging from $[-1,1]$ is the fundamental relational matrix or connection or adjacency matrix.

\subsection{Instantaneous vector}

It is the vector which denotes the $\mathrm{ON}$ and OFF position of the nodes at an epoch of time

\subsection{Fixed Point}

The fixed point is a unique state vector denoting the equilibrium state of a dynamical system with the hidden pattern of the cyclic FCM containing the feedback.

\subsection{Limit cycle} the FCM.

The settling point of the state vectors is the limit cycle of

\subsection{Fuzzy Cognitive Multimaps}

Fuzzy cognitive Multimaps are fuzzy signed directed multi graphs withc ${ }^{\mathrm{p}_{\mathrm{ij}}}$, the factors as nodes and $\mathrm{e}_{\mathrm{ij}} \mathrm{p}_{\mathrm{p}}=$ $1,2, \ldots \mathrm{n})$ as the edges denoting the relativity.

\subsection{Fuzzy Cognitive Linguistic Multimaps}

Fuzzy Cognitive Linguistic Multimaps assumes the edges $\mathrm{e}^{\mathrm{p}} \mathrm{ij}_{\mathrm{j}}(\mathrm{p}=1,2 \ldots \mathrm{n})$ weights from the linguistic variables.

\subsection{Heptagonal Fuzzy Number}

A Heptagonal fuzzy number $\tilde{H}$ will be of the form $\left(\mathrm{a}_{1}, \mathrm{a}_{2}, \mathrm{a}_{3}, \mathrm{a}_{4}, \mathrm{a}_{5}, \mathrm{a}_{6}, \mathrm{a}_{7}\right)$ has the membership function $\mu_{H}(x)$ represented graphically in Fig.2.1.

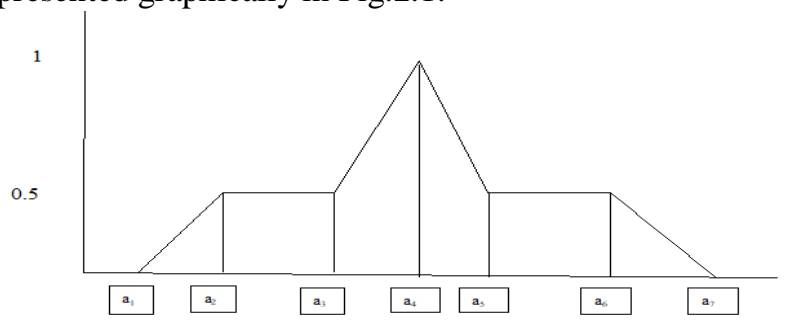

Fig.2.1. Membership Function

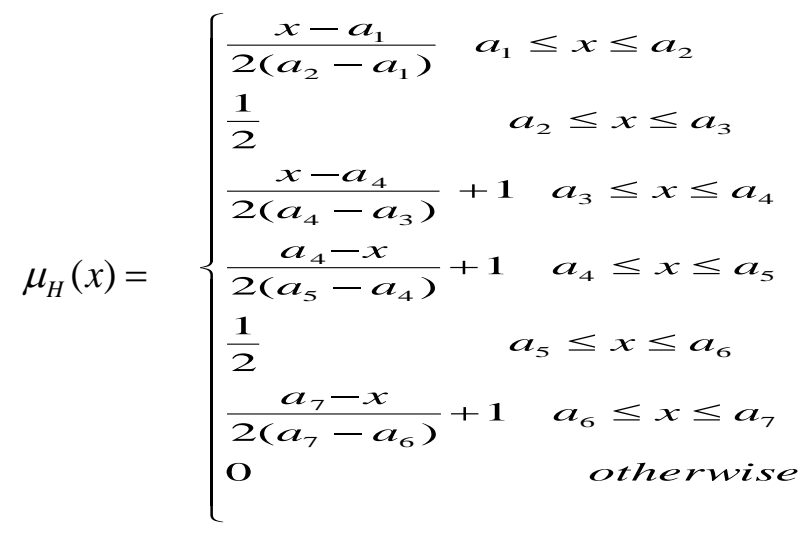

\section{METHODOLOGY}

The following steps are applied in determining the fixed point of Fuzzy Cognitive Linguistic Multimaps [10].

i. The factors associated with the problem considered for the study are determined based on the opinion of the experts.

ii. (ii)The relational matrix M1,M2,...Mn representing the association and the causal effects in terms of linguistic variables between the factors of the study is formulated based on each expert's outlook.

iii. The union of the relational matrices is considered as the multimatrix $\mathrm{M}, \mathrm{M}=\mathrm{M} 1 \mathrm{UM} 2 \mathrm{UM} 3 . . . \mathrm{Mn}$.

iv. The instantaneous state multivector of the form (10000..0) U(01000..0)U....(000001000.0) is passed into the Relational multimatrix $\mathrm{M}$.

v. The obtained vector is threshold by assigning 1 to the maximum value and the respective factor considered being in $\mathrm{ON}$ position and 0 to the rest.

vi. (vi)The steps are repeated until the fixed point or the limit cycle is obtained

\section{APPLICATION TO THE PROBLEM CONSIDERED}

Several researchers have analyzed the causes of inequality between education and employability. Few of the significant and relevant contributions are cited as follows, Dev.et.al [2] presented the comparative status of employment and unemployment in youth. Kumar [4] mapped the spatial and 
temporal dimension of skills and education profiles of India's workforce and insisted on the need of skill based curriculum. Raju Sarkar [9] discussed the various issues of employment and education of women in west Bengal but he described the factors hurdling the bridging of education and employment without gender disparity.

Based on the literature of the earlier works, educationalist and other experts in the related field, the study factors that place education and employment at extreme poles are presented as follows.

F1 Lack of skill based curriculum.

F2 Obsolete methods of teaching

F3 Less focus on fostering employability skills amidst the student community

F4 Deficit of interest in teachers to adopt the upcoming trends in educational technology

F5 Institutions are self-centric and market education without promoting the quality.

F6 Lack of opportunities to the students to drift towards varying learning trends

F7 Infrastructure supporting technology based educational system is feeble in institutions.

Based on the linguistic questionnaire, the relational matrix is obtained from the experts.

Relational matrix given by the first expert

$\begin{array}{lccccccc} & \text { F1 } & \text { F2 } & \text { F3 } & \text { F4 } & \text { F5 } & \text { F6 } & \text { F7 } \\ \text { F1 } & \text { 0 } & \text { M } & \text { H } & \text { H } & \text { L } & \text { H } & \text { H } \\ \text { F2 } & \text { L } & \text { 0 } & \text { L } & \text { H } & \text { L } & \text { H } & \text { H } \\ \text { F3 } & \text { M } & \text { M } & \text { 0 } & \text { L } & \text { L } & \text { H } & \text { L } \\ \text { F4 } & \text { L } & \text { M } & \text { M } & \text { 0 } & \text { L } & \text { H } & \text { H } \\ \text { F5 } & \text { H } & \text { M } & \text { M } & \text { L } & \text { 0 } & \text { H } & \text { H } \\ \text { F6 } & \text { M } & \text { L } & \text { M } & \text { L } & \text { M } & \text { 0 } & \text { M } \\ \text { F7 } & \text { L } & \text { M } & \text { L } & \text { M } & \text { M } & \text { M } & \text { 0 }\end{array}$

The relational matrix given by the second expert

$\begin{array}{llllllll} & \text { F1 } & \text { F2 } & \text { F3 } & \text { F4 } & \text { F5 } & \text { F6 } & \text { F7 } \\ \text { F1 } & \text { 0 } & \text { M } & \text { H } & \text { H } & \text { L } & \text { H } & \text { H } \\ \text { F2 } & \text { L } & \text { 0 } & \text { L } & \text { H } & \text { L } & \text { H } & \text { H } \\ \text { F3 } & \text { M } & \text { M } & \text { 0 } & \text { L } & \text { L } & \text { H } & \text { L } \\ \text { F4 } & \text { L } & \text { M } & \text { M } & \text { 0 } & \text { L } & \text { H } & \text { H } \\ \text { F5 } & \text { H } & \text { M } & \text { M } & \text { L } & \text { 0 } & \text { H } & \text { H } \\ \text { F6 } & \text { M } & \text { L } & \text { M } & \text { L } & \text { M } & \text { 0 } & \text { M } \\ \text { F7 } & \text { L } & \text { M } & \text { L } & \text { M } & \text { M } & \text { M } & \text { 0 }\end{array}$

The relational matrix given by the third expert

$\begin{array}{llllllll} & \text { F1 } & \text { F2 } & \text { F3 } & \text { F4 } & \text { F5 } & \text { F6 } & \text { F7 } \\ \text { F1 } & 0 & \text { M } & \text { H } & \text { H } & \text { L } & \text { H } & \text { H } \\ \text { F2 } & \text { L } & \text { 0 } & \text { L } & \text { H } & \text { L } & \text { H } & \text { H } \\ \text { F3 } & \text { M } & \text { M } & \text { 0 } & \text { L } & \text { L } & \text { H } & \text { L } \\ \text { F4 } & \text { L } & \text { M } & \text { M } & \text { 0 } & \text { L } & \text { H } & \text { H } \\ \text { F5 } & \text { H } & \text { M } & \text { M } & \text { L } & \text { 0 } & \text { H } & \text { H } \\ \text { F6 } & \text { M } & \text { L } & \text { M } & \text { L } & \text { M } & \text { 0 } & \text { M } \\ \text { F7 } & \text { L } & \text { M } & \text { L } & \text { M } & \text { M } & \text { M } & 0\end{array}$

The relational matrix given by the fourth expert

$\begin{array}{lccccccc} & \text { F1 } & \text { F2 } & \text { F3 } & \text { F4 } & \text { F5 } & \text { F6 } & \text { F7 } \\ \text { F1 } & \text { 0 } & \text { M } & \text { H } & \text { H } & \text { L } & \text { H } & \text { H } \\ \text { F2 } & \text { L } & \text { 0 } & \text { L } & \text { H } & \text { L } & \text { H } & \text { H } \\ \text { F3 } & \text { M } & \text { M } & \text { 0 } & \text { L } & \text { L } & \text { H } & \text { L } \\ \text { F4 } & \text { L } & \text { M } & \text { M } & 0 & \text { L } & \text { H } & \text { H } \\ \text { F5 } & \text { H } & \text { M } & \text { M } & \text { L } & \text { 0 } & \text { H } & \text { H } \\ \text { F6 } & \text { M } & \text { L } & \text { M } & \text { L } & \text { M } & 0 & \text { M } \\ \text { F7 } & \text { L } & \text { M } & \text { L } & \text { M } & \text { M } & \text { M } & 0\end{array}$

The relational matrix given by the fifth expert $\begin{array}{lllllll}\text { F1 } & \text { F2 } & \text { F3 } & \text { F4 } & \text { F5 } & \text { F6 } & \text { F7 }\end{array}$

$\begin{array}{llllllll}\text { F1 } & 0 & \text { M } & \text { H } & \text { H } & \text { L } & \text { H } & \text { H } \\ \text { F2 } & \text { L } & \text { 0 } & \text { L } & \text { H } & \text { L } & \text { H } & \text { H } \\ \text { F3 } & \text { M } & \text { M } & 0 & \text { L } & \text { L } & \text { H } & \text { L } \\ \text { F4 } & \text { L } & \text { M } & \text { M } & 0 & \text { L } & \text { H } & \text { H } \\ \text { F5 } & \text { H } & \text { M } & \text { M } & \text { L } & 0 & \text { H } & \text { H } \\ \text { F6 } & \text { M } & \text { L } & \text { M } & \text { L } & \text { M } & 0 & \text { M } \\ \text { F7 } & \text { L } & \text { M } & \text { L } & \text { M } & \text { M } & \text { M } & 0\end{array}$

The Heptagonal quantification of linguistic terminologies is as follows

\begin{tabular}{|c|c|c|}
\hline $\begin{array}{c}\text { Linguistic } \\
\text { Variable }\end{array}$ & Heptagonal Weight & Average \\
\hline Low & $(0,0.1,0.2,0.3,0.35,0.4,0.45)$ & $\mathbf{0 . 2 6}$ \\
\hline Medium & $(0.4,0.45,0.5,0.55,0.6,0.65,0.7)$ & $\mathbf{0 . 5 5}$ \\
\hline High & $(0.65,0.7,0.8,0.9,1,1,1)$ & $\mathbf{0 . 8 6}$ \\
\hline
\end{tabular}

The modified relational matrices given by the expert

$\begin{array}{llllllll}\text { I } & \text { F1 } & \text { F2 } & \text { F3 } & \text { F4 } & \text { F5 } & \text { F6 } & \text { F7 } \\ \text { Expert } & & & & & & & \\ \text { F1 } & 0 & 0.55 & 0.86 & 0.86 & 0.26 & 0.86 & 0.86 \\ \text { F2 } & 0.26 & 0 & 0.26 & 0.86 & 0.26 & 0.86 & 0.86 \\ \text { F3 } & 0.55 & 0.55 & 0 & 0.26 & 0.26 & 0.86 & 0.26 \\ \text { F4 } & 0.26 & 0.55 & 0.55 & 0 & 0.26 & 0.86 & 0.86 \\ \text { F5 } & 0.86 & 0.55 & 0.55 & 0.26 & 0 & 0.86 & 0.86 \\ \text { F6 } & 0.55 & 0.26 & 0.55 & 0.26 & 0.55 & 0 & 0.55 \\ \text { F7 } & 0.26 & 0.55 & 0.26 & 0.55 & 0.55 & 0.55 & 0\end{array}$

$\begin{array}{llllllll}\text { II-Expert } & \text { F1 } & \text { F2 } & \text { F3 } & \text { F4 } & \text { F5 } & \text { F6 } & \text { F7 } \\ \text { F1 } & 0 & 0.55 & 0.86 & 0.86 & 0.26 & 0.86 & 0.86 \\ \text { F2 } & 0.26 & 0 & 0.26 & 0.86 & 0.26 & 0.86 & 0.86 \\ \text { F3 } & 0.55 & 0.55 & 0 & 0.26 & 0.26 & 0.86 & 0.26 \\ \text { F4 } & 0.26 & 0.55 & 0.55 & 0 & 0.26 & 0.86 & 0.86 \\ \text { F5 } & 0.86 & 0.55 & 0.55 & 0.26 & 0 & 0.86 & 0.86 \\ \text { F6 } & 0.55 & 0.26 & 0.55 & 0.26 & 0.55 & 0 & 0.55 \\ \text { F7 } & 0.26 & 0.55 & 0.26 & 0.55 & 0.55 & 0.55 & 0\end{array}$




\begin{tabular}{|c|c|c|c|c|c|c|c|c|c|c|c|c|}
\hline $\begin{array}{c}\text { III- } \\
\text { Expert }\end{array}$ & $\mathrm{F} 1$ & $\mathrm{~F} 2$ & F3 & F4 & F5 & F6 & F7 & $\begin{array}{c}\text { IV- } \\
\text { Expert }\end{array}$ & $\mathrm{F} 1$ & $\mathrm{~F} 2$ & F3 & F4 \\
\hline $\mathrm{F} 1$ & 0 & 0.55 & 0.86 & 0.86 & 0.26 & 0.86 & 0.86 & F1 & 0 & 0.55 & 0.86 & 0.86 \\
\hline $\mathrm{F} 2$ & 0.26 & 0 & 0.26 & 0.86 & 0.26 & 0.86 & 0.86 & $\mathrm{~F} 2$ & 0.26 & 0 & 0.26 & \\
\hline F3 & 0.55 & 0.55 & 0 & 0.26 & 0.26 & 0.86 & 0.26 & F3 & 0.55 & 0.55 & 0 & \\
\hline $\mathrm{F} 4$ & 0.26 & 0.55 & 0.55 & 0 & 0.26 & 0.86 & 0.86 & F4 & 0.26 & 0.55 & 0.55 & \\
\hline F5 & 0.86 & 0.55 & 0.55 & 0.26 & 0 & 0.86 & 0.86 & F5 & 0.86 & 0.55 & 0.55 & \\
\hline F6 & 0.55 & 0.26 & 0.55 & 0.26 & 0.55 & 0 & 0.55 & F6 & 0.55 & 0.26 & 0.55 & \\
\hline F7 & 0.26 & 0.55 & 0.26 & 0.55 & 0.55 & 0.55 & 0 & F7 & 0.26 & 0.55 & 0.26 & \\
\hline & & & \multicolumn{2}{|c|}{$\begin{array}{c}\mathrm{V}- \\
\text { Expert }\end{array}$} & $\mathrm{F} 1$ & $\mathrm{~F} 2$ & $\mathrm{~F} 3$ & $\mathrm{~F} 4$ & F5 & & F6 & F7 \\
\hline & & & \multicolumn{2}{|c|}{ F1 } & 0 & 0.55 & 0.86 & 0.86 & 0.26 & & 0.86 & \\
\hline & & & \multicolumn{2}{|c|}{$\mathrm{F} 2$} & 0.26 & 0 & 0.26 & 0.86 & 0.26 & & 0.86 & \\
\hline & & & \multicolumn{2}{|c|}{ F3 } & 0.55 & 0.55 & 0 & 0.26 & 0.26 & & 0.86 & \\
\hline & & & \multicolumn{2}{|c|}{$\mathrm{F} 4$} & 0.26 & 0.55 & 0.55 & 0 & 0.26 & & 0.86 & \\
\hline & & & \multicolumn{2}{|c|}{ F5 } & 0.86 & 0.55 & 0.55 & 0.26 & 0 & & 0.86 & \\
\hline & & & \multicolumn{2}{|c|}{ F6 } & 0.55 & 0.26 & 0.55 & 0.26 & 0.55 & & 0 & \\
\hline & & & \multicolumn{2}{|c|}{ F7 } & 0.26 & 0.55 & 0.26 & 0.55 & 0.55 & & 0.55 & \\
\hline
\end{tabular}

The method of determining the fixed point is based on the research work of VasanthaKandasamy, in which the author has determined the fixed point and the limit cycle of the dynamical system with the opinion of two experts in Fuzzy Cognitive Trimaps model. The same fashion of computing the fixed point is used in this research work with Fuzzy cognitive multimaps.

Let $\mathrm{X}=\mathrm{X} 1 \mathrm{U}$ X2 U X3 U X4 U X5 and M =M1 U M2 U M3 U M4 U M5

$\mathrm{XM}=(\mathrm{X} 1 \mathrm{U}$ X2 U X3 U X4 U X5) $\mathrm{M}$ U M5) = $(\mathrm{X} 1 \mathrm{U} X 2 \mathrm{U} X 3 \mathrm{U}$ X4 U X5)(M1 U M2 U M3 U M4

$=\mathrm{X} 1 \mathrm{M} 1 \mathrm{U}$ X2M2 U X3M3 U X4M4U X5M5

Let $X=(1000000) U(0100000) U(0010000) U(0001000)$ $\mathrm{U}(0000100)$ be the initial state multivector.

$\mathrm{XM}=(1000000) \mathrm{M} 1 \mathrm{U}(0100000) \mathrm{M} 2 \mathrm{U}(0010000) \mathrm{M} 3$ U(0001000)M4 U (0000100)M5

$=\left(\begin{array}{lllllll}0 & 0.55 & 0.86 & 0.86 & 0.26 & 0.86 & 0.86\end{array}\right) \mathrm{U}\left(\begin{array}{llll}0.26 & 0 & 0.26 & 0.86\end{array}\right.$

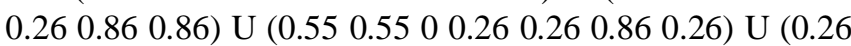
$\left.\begin{array}{llllllllllllllll}0.55 & 0.55 & 0 & 0.26 & 0.86 & 0.86\end{array}\right) \mathrm{U}\left(\begin{array}{llllll}0.86 & 0.55 & 0.55 & 0.26 & 0 & 0.86\end{array}\right.$ $0.86)$

The above multivector is threshold and the new multivector is passed into the relational matrix $\mathrm{M}$.

$\rightarrow$ (1011011)M1 U (0101011)M2 U (0010010)M3 U (0001011)M4 U (1000111)M5

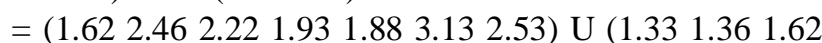

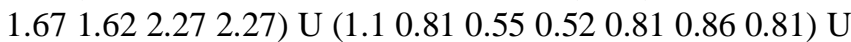
(1.07 $1.361 .360 .81 \quad 1.361 .411 .41)$ U (1.67 1.912 .221 .92 $1.362 .272 .27)$

$\rightarrow(0000010) \mathrm{U}(0000011) \mathrm{U}(1000000) \mathrm{U}(0000011) \mathrm{U}$ (0000011)

By repeating in the same fashion the limit cycleis obtained. $=(1010101) \mathrm{U}(0000100) \mathrm{U}(0011011) \mathrm{U}(0000100) \mathrm{U}$ (0000100)

$=(0000010) \mathrm{U}(1000011) \mathrm{U}(0000010) \mathrm{U}(1000011) \mathrm{U}$ (1000011)

$=(1010101) \mathrm{U}(0011000) \mathrm{U}(1010101) \mathrm{U}(0011000) \mathrm{U}$ (0011000)
$\mathrm{T}=(0000010) \mathrm{U}(0000010) \mathrm{U}(0000010) \mathrm{U}(0000010) \mathrm{U}$ (0000010) is the resultant multivector.

Let X $=$ X1 U X2 U X3 U X4 U X5

M =M1 U M2 U M3 U M4 U M5

$\mathrm{XM}=(\mathrm{X} 1 \mathrm{U}$ X2 U X3 U X4 U X5) $\mathrm{M}$

$=(X 1$ U X2 U X3 U X4 U X5)(M1 U M2 U M3 U M4 U M5)

= X1M1U X2M2 U X3M3 U X4M4U X5M5

$=(1000000) \mathrm{M} 1 \mathrm{U}(0100000) \mathrm{M} 2 \mathrm{U}(0010000) \mathrm{M} 3 \mathrm{U}$ (0000010)M4 U (0000001)M5

$=\left(\begin{array}{lllllll}0 & 0.55 & 0.86 & 0.86 & 0.26 & 0.86 & 0.86\end{array}\right) \mathrm{U}\left(\begin{array}{llll}0.26 & 0 & 0.26 & 0.86\end{array}\right.$

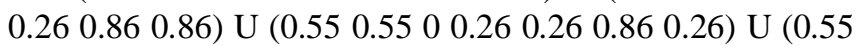
$0.260 .550 .260 .5500 .55)$ U (0.26 0.550 .260 .550 .550 .55 0)

$\rightarrow(1011011) \mathrm{M} 1 \quad \mathrm{U}(0101011) \mathrm{M} 2 \quad \mathrm{U}(0010010) \mathrm{M} 3 \mathrm{U}$ (1010111)M4 U (0101111)M5

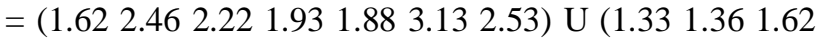

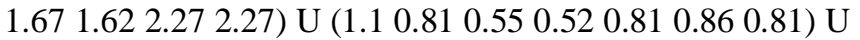
(2.22 2.462 .222 .191 .623 .132 .53$)$ U (2.19 $1.912 .17 \quad 1.93$ $1.623 .133 .13)$

$\rightarrow(0000010) \mathrm{U}(0000011) \mathrm{U}(1000000) \mathrm{U}(0000011) \mathrm{U}$ (0000011)

By repeating in the same fashion the following multi vectors are obtained.

$=(1010101) \mathrm{U}(0000100) \mathrm{U}(0011011) \mathrm{U}(0000010) \mathrm{U}$ (0000100)

$=(0000010) \quad \mathrm{U} \quad(1000011) \quad \mathrm{U} \quad(0000010) \quad \mathrm{U}$ (1010111)U(1000011)

$=(1010101) \mathrm{U}(0011000) \mathrm{U}(1010101) \mathrm{U}(0000010) \mathrm{U}$ (0011011)

$\mathrm{T}^{\prime}=(0000010) \mathrm{U}(0000010) \mathrm{U}(0000010) \mathrm{U}(0000010) \mathrm{U}$ (0000010)is the resultant multivector. 


\section{RESULTS AND DISCUSSION}

The factors F1,F2,F3,F4\& F5 are kept in ON position to determine the impact on the other factors. The final resultant multi vector is (0000010) $\mathrm{U}(0000010) \mathrm{U}(0000010) \mathrm{U}$ (0000010) $\mathrm{U}(0000010)$ and the implication lies at the factor F6, lack of opportunities to the students to drift towards varying learning trends.

At another case, the factors F1, F2, F3, F6, F7 are kept in ON position to determine the impact on other factors. The final obtained multi vector is (0000010) $\mathrm{U}(0000010) \mathrm{U}$ (0000010) U (0000010) U (0000010). This is the limit cycle and the fixed point of this dynamical system. The same steps can be repeated by keeping other combination of factors in ON position to determine its consequential impacts.

The final multivector reflects that the higher educational institutions should develop a curriculum framework to enable the graduates to possess the attributes such as communication skills, problem solving, critical thinking, analytical reasoning, reflective thinking, multicultural competence, self-directed learning, digital literacy, lifelong learning. These graduate attributes are the employer's expected qualities of his recruits. To equip the students with these graduate attributes, the educational institutions must provide them various opportunities for learning to take place at one's own pace. It is the responsibility of the institutions to cultivate the practices of effective learning with the assistance of technology to enable the students to stay connected with the academics.

\section{CONCLUSION}

This paper presents the Fuzzy Cognitive Multimaps model which is an extension of Fuzzy Cognitive Trimaps model. This research work predominantly focuses on the factors contributing for positioning education and employment at two poles and determines the core factor of contribution. The inferences from this research study strongly emphasize that the learnersmust be provided ample opportunities for making their learning to take place. Learner centric curriculum integrated with employability skills can reinforce the student community to battle the competition in the job market. This research work can be extended by using other higher order fuzzy numbers to quantify the linguistic variablesor comparative analysis can be made with fuzzy numbers of different orders to check the validity of the results.

\section{REFERENCES}

1. Axelord. R.(ed.) Structure of decision: The cognitive Maps of Political Elites, Princeton Univ. Press, New Jersey, 1976.

2. Dev, Mahendra\&Motkuri, Venkatanarayana.(2011). Youth employment and unemployment in India.

3. Kosko.B ,Fuzzy cognitive maps, International journal of Man-Machine studies, (1988), 62-75.

4. Kumar, M. Satish,Employment Growth, Education and Skills in India: Emerging Perspectives, Indian Journal of Labour Economics. 56. 95-122,2013.

5. Nivetha Martin ,Contemporary challenges of digital marketing : Ranking Analysis by Fuzzy Cognitive Maps" International journal of basic and applied research,vol-9, issue-6, 268-272, ISSN 2249-3352, 2019

6. Nivetha Martin, "Ranking the benefits of online learning in students perspective using linguistic Fuzzy Cognitive Maps" Journal Applied Science and computatiuon ,vol -6, issue-4, 158-164, 2019.
7. Nivetha Martin," Resolving manpower allocation problem using LDIFS and NEDM, journal of Applied science and computation, vol-6, Issue-4 1145-1149,2019.

8. Nivetha Martin,"An Analysis of driving performance error using Fuzzy Triangular Four Matrix" International Journal of Applied Engineering,Vol-10,Issue-85,423-429.2015

9. Raju Sarkar, Recent Status of Education, Employment and Empowerment of Women in West Bengal ,International Journal of Scientific and Research Publications, Volume 7, Issue 1, 263-269,2017.

10. Vasantha Kanthasamy.W.B.,Florentin Smarandache.,Application of Bimatrices to some Fuzzy and Neutrosophic Models, 2005. 